\title{
Vertical Loads Effects Applied on the Pavement Considering the Variation on Tire Pressure
}

Pablo Yugo Yoshiura Kubo ${ }^{1}$, Cassio Eduardo Lima de Paiva ${ }^{1}$, Adelino Jorge Lopes Ferreira ${ }^{2}$, Arthur Eduardo de Freitas Larocca ${ }^{3}$ and Glaucio Rogerio Cararo ${ }^{4}$

1. Department of Civil Engineering, University of Campinas, Campinas 13083-852, Brazil

2. Department of Civil Engineering, University of Coimbra, Coimbra 3030-788, Portugal

3. Department of Mechanical Engineering, Alpha Technical Services, Curitiba 80520-590, Brazil

4. Chassis and Vehicle Dynamic Engineering, Volvo Group Latin America, Curitiba 81290-000, Brazil

\begin{abstract}
The main objective of this paper is to analyse the vertical loads effects applied on the pavement, considering the variation of tire pressure, from a truck's front suspension. For the measurements, a durability test track located in Brazil has been used. The tire pressure was increased by 10 psi from 90 psi to 130 psi with a constant load of $6 \mathrm{t}$ on the front suspension, the maximum allowed load for front axle according to Brazilian legislation. By applying relative damage concept, it is possible to conclude that the variation on the tire pressure will not affect significantly the load applied on the pavement. However, it is recommended to repeat the same methodology in order to analyse the influence on the variation of the other quarter car model variants.
\end{abstract}

Key words: Vertical load, pavement, relative damage.

\section{Introduction}

\subsection{Background}

Besides impacting directly on the vehicle dynamic behavior (rolling resistance, ride and handling, fuel economy, noise, vibration and harshness), the tire-road interaction is also a factor that compromises the pavement integrity. As larger loads and vehicles appear in the road transportation system, pavement damage concerns are taking greater relevance in road construction and maintenance activities [1, 2].

Vertical dynamic load is directly related to the deterioration of the pavement [3]. Therefore, this relation can also be extended for the vehicles variants, especially for the commercial vehicles (trucks and buses).

By analysing the quarter car model (Fig. 1) [4], it is expected that the tire spring rate could influence it by

\footnotetext{
Corresponding author: Pablo Yugo Yoshiura Kubo, Ph.D., engineer, research field: pavements. E-mail: pyykubo@hotmail.com.
}

changing the tire pressure.

Some authors suggest relationship between pavement damage, due to tire interaction, such as braking [5], different tires configurations [6, 7], and even due to different tire pressures [8], but still lack of studies that correlate tire pressure with vertical dynamic load applied to the pavement.

\subsection{Boundaries and Assumptions}

In order to analyse the influence of the tire pressure, it is necessary to keep constant the other variants of the quarter car model (Fig. 1):

- sprung mass and unsprung mass: set as $6 \mathrm{t}$, the maximum allowed weight on the front axle according to the Brazilian legislation;

- primary suspension spring rate and shock absorber damping forces: set according to the manufacture specification—new components;

- pavement longitudinal profile: the tests have been 


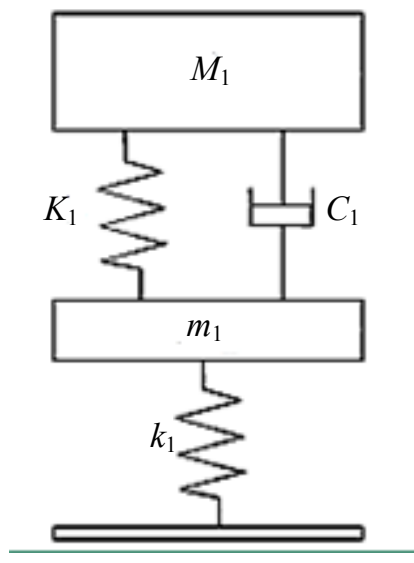

Fig. 1 Quarter car model [4].

$M_{1}$ : sprung mass; $K_{1}$ : primary suspension spring rate; $c_{1}$ : shock absorber damping force; $m_{1}$ : unsprung mass; $k_{1}$ : tire spring stiffness.

performed on a proving ground located in Brazil, in order to keep the same track in all measurements;

- rigid truck with the configuration of two steering axles, one drive and one tag axle (Fig. 2), which consists in one driven axle and three non-driven axles, has been chosen and all measurements reflect the loads of both front steering axles.

\section{Methodology}

\subsection{Metal-Foil Strain Gauge}

The metal-foil strain gauges (Fig. 3), also identified as metal-foil resistance strain gauges, are sensors composed by a thin resistive foil, fixed on an electrical insulation material, usually polyamide or epoxy-phenolic resin, called base [9].

The main advantages and characteristics of the metal-foil strain gauges are [10]:

- high precision and linearity;

- low cost and weight;

- good dynamic and static response;

- use in wide range of temperature and vibration.

The working principle of this strain gauge is based on the fact that all electrical conductors change their resistance when elongated [11]. This characteristic is stated in the second Ohm's Law, which relates the resistance $(R)$ of a conductor to its length $(L)$, cross-sectional area $(A)$ and resistivity $(\rho)$ :

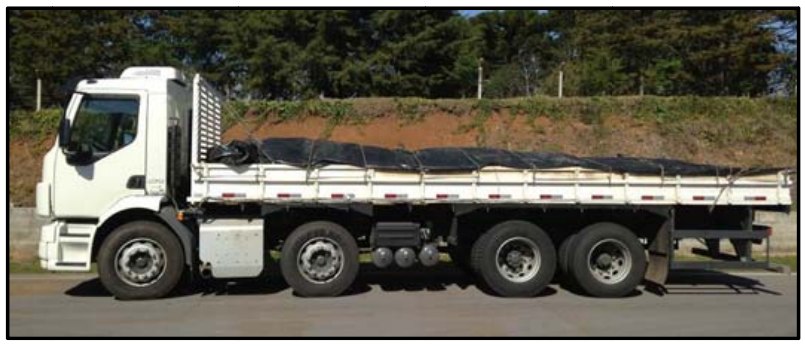

Fig. 2 Tested truck.

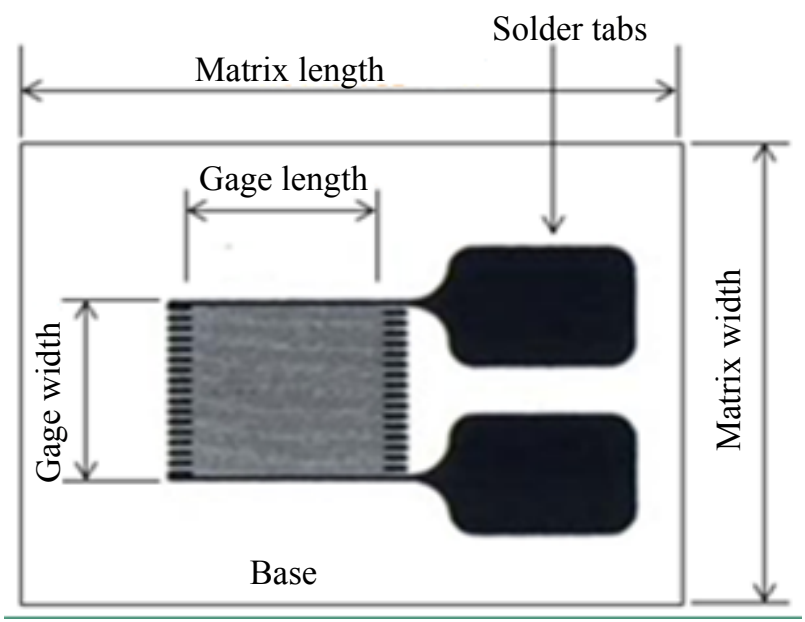

Fig. 3 Illustration of a metal-foil strain gauge [12].

$$
R=\frac{\rho L}{A}
$$

Considering a generic elongation in an electrical conductor, Eq. (2) can be rewritten as follows [5]:

$$
\frac{\Delta R}{R}=\frac{k \Delta L}{L}
$$

where, the factor $k$ is defined as the sensitivity of the strain gauge, corresponding to a constant that varies with the resistive material used. Its value varies between 2 and 4, for most alloys used, and shall not be related to the magnitude of the measured strain $[9,12]$.

Considering that the giving strain is measured as the total elongation per unit length of material [9], the following equation is obtained:

$$
\frac{\Delta R}{R}=k \varepsilon
$$

Eq. (3) indicates that the magnitude of the measured strain $(\varepsilon)$ is proportional to a relative change in the resistance, which is the working principle of this type of sensor [9].

As the strain gauge resistance changes, the strain results are computed through the electric circuit of a Wheatstone bridge (Fig. 4). This is mainly due to the 


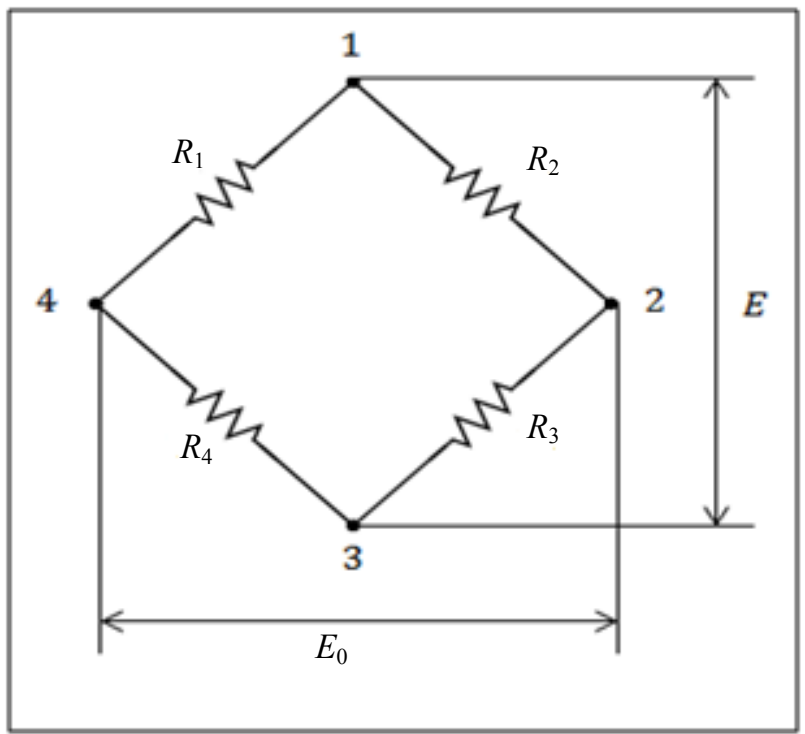

Fig. 4 Illustration of a Wheatstone bridge circuit [13].

capacity of this circuit to detect small changes in resistance $\left(R_{1}\right.$ to $\left.R_{4}\right)$, and to allow temperature compensation and also voltage adjustment $\left(E\right.$ and $\left.E_{0}\right)$ [13].

The Wheatstone bridge consists of four resistive arms $\left(R_{1}, R_{2}, R_{3}\right.$ and $\left.R_{4}\right)$ connected to a supply voltage, where each arm can be connected to one or more strain gauges [14].

Several arrangements of strain gauges and resistances are possible in this circuit (1/4 bridge, 1/2 symmetric/asymmetric bridge and full bridge), each one with a specific application. Fig. 5 illustrates the quarter-bridge arrangement, the same used in this methodology.

Finally, the result is obtained by associating the strain to an electrical signal (analogue), which subsequently will be conditioned in a data acquisition system [15].

\subsection{Instrumentation and Calibration}

Uniaxial strain gauges were placed on the main leave spring of the 1 st and 2nd steering axle (Fig. 6) on the LHS (left hand side) and RHS (right hand side) of the vehicle.

The recorded values given by the mentioned instrumentation were in $\mu e$ (micro-strain). Therefore, it was necessary to calibrate the system in order to estimate the force applied on the pavement.

A weighting scale has been used and different loads have been applied on the vehicle body with the objective of having the calibration curves between $\mu e$ and the load applied on the ground in tons (Figs. 7 and 8).

Due to the fact that all tested springs have the same spring rate, all calibration curves have similar characteristics.

For the test procedure, a pothole track has been used in the proving ground for the measurements with the following conditions (Figs. 9 and 10):

- vehicle weight: 6 t per front axle;

- vehicle speed: $40 \mathrm{~km} / \mathrm{h}$;

- new shock absorbers;

- new spring unit;

- tire size: 295/80 R22.5.

It is important to highlight that most of the events on the left and right hand sides of the pot hole track are different, so different loads on both sides of the vehicle would be expected.

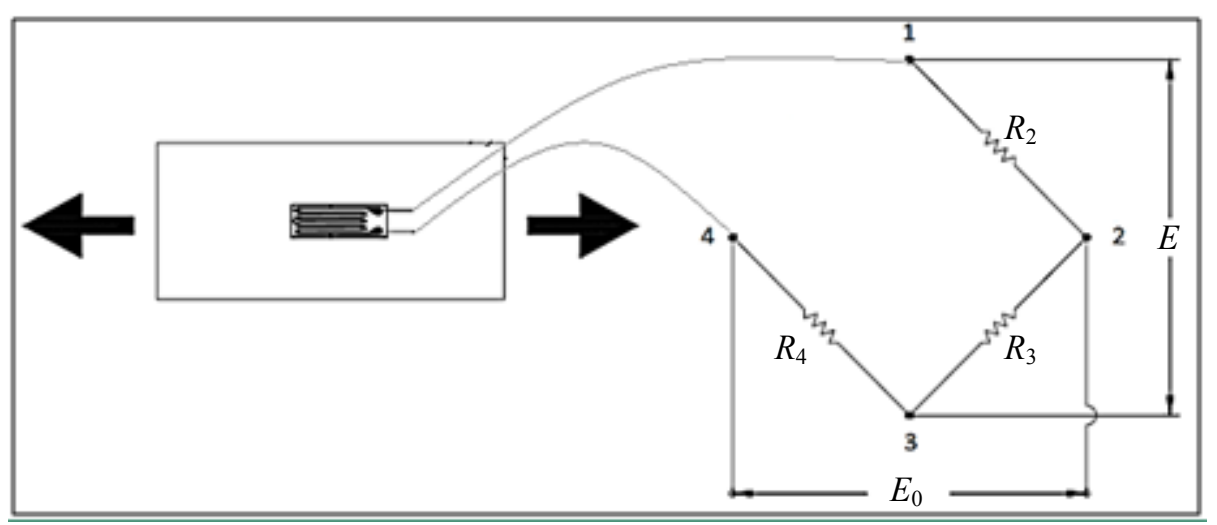

Fig. 5 Tensile test: strain gauge with quarter-bridge arrangement [9]. 


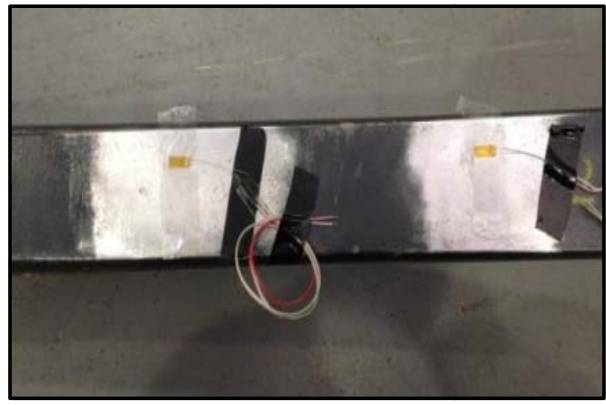

Fig. 6 Primary suspension spring leaf-instrumentation.

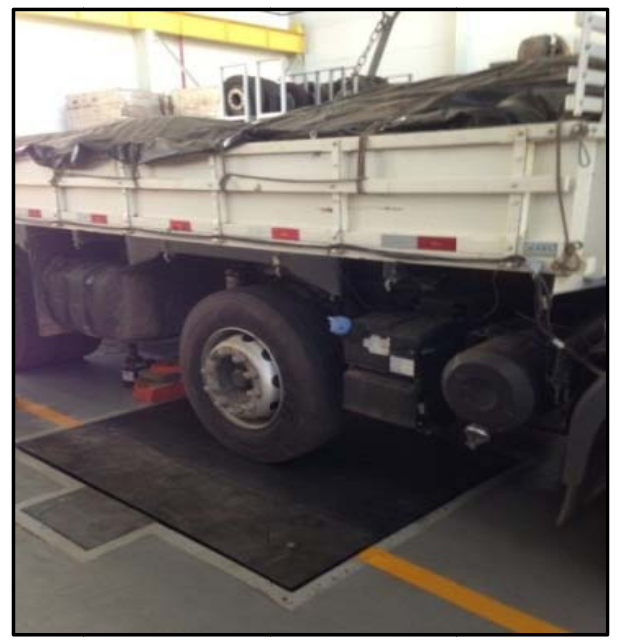

Fig. 7 Weighting scale used for the calibration.

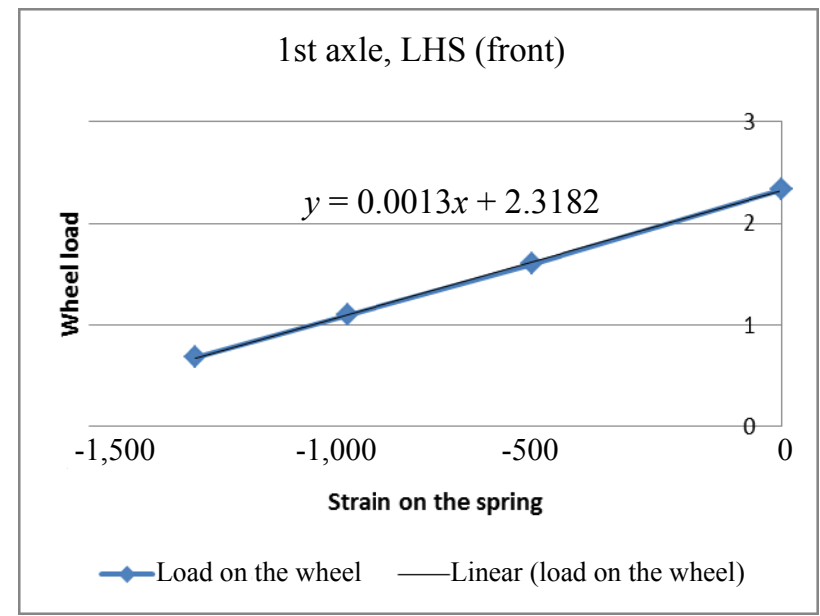

Fig. 8 Example of one spring calibration.

The only variant set was the tire pressure:

- 90 psi (621 kPa);

- 100 psi (690 kPa);

- $110 \mathrm{psi}(758 \mathrm{kPa})$ - recommended pressure for the applied vehicle weight;

- 120 psi $(827 \mathrm{kPa})$;
- 130 psi (896 kPa).

Three measurements with each tire pressure configuration have been performed.

\section{Analysis and Results}

Fig. 11 presents an example of the time signal of each front spring for a shock absorber condition (new). The mentioned figure refers to the load applied to the pavement on each front axle tires in tons.

By analysing the time signal data, it is not possible to make conclusions. Therefore, it was necessary to use other statistical analysis.

Fig. 12 presents one of the histograms for the tested tire pressures. It is possible to visualize on this figure that the counting cycles close to the static load (3t) are the mandatory values. Nevertheless, with this statistical tool, it is not possible to analyze the behavior of the other loads to the pavement.

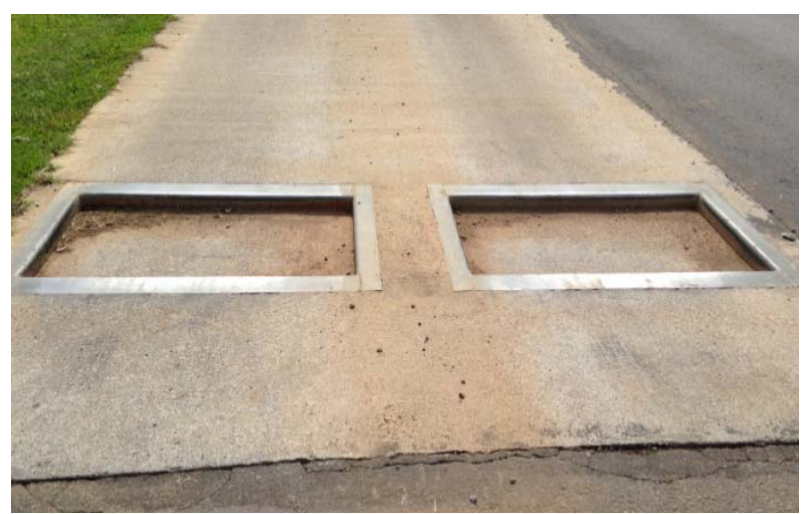

Fig. 9 Detail of the pothole track.

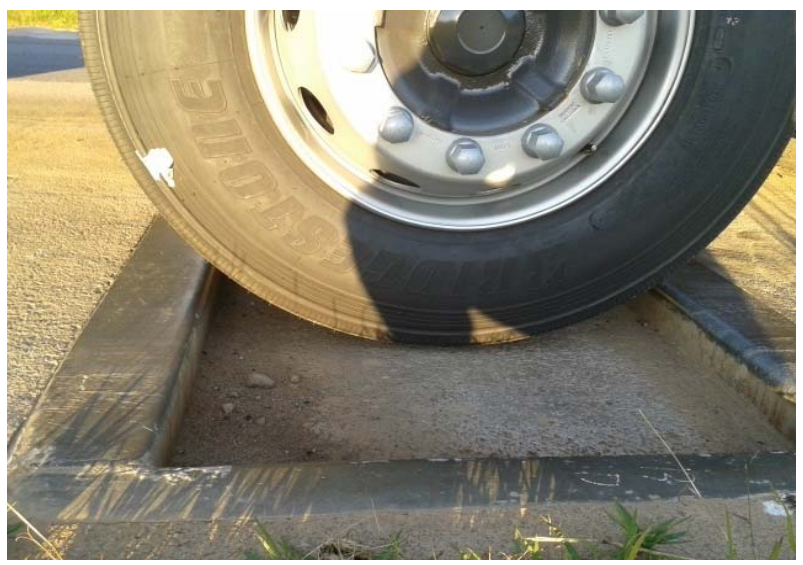

Fig. 10 Interaction between tire and pothole. 
Load applied on the pavement-tire pressure: $110 \mathrm{psi}(758 \mathrm{kPa})$
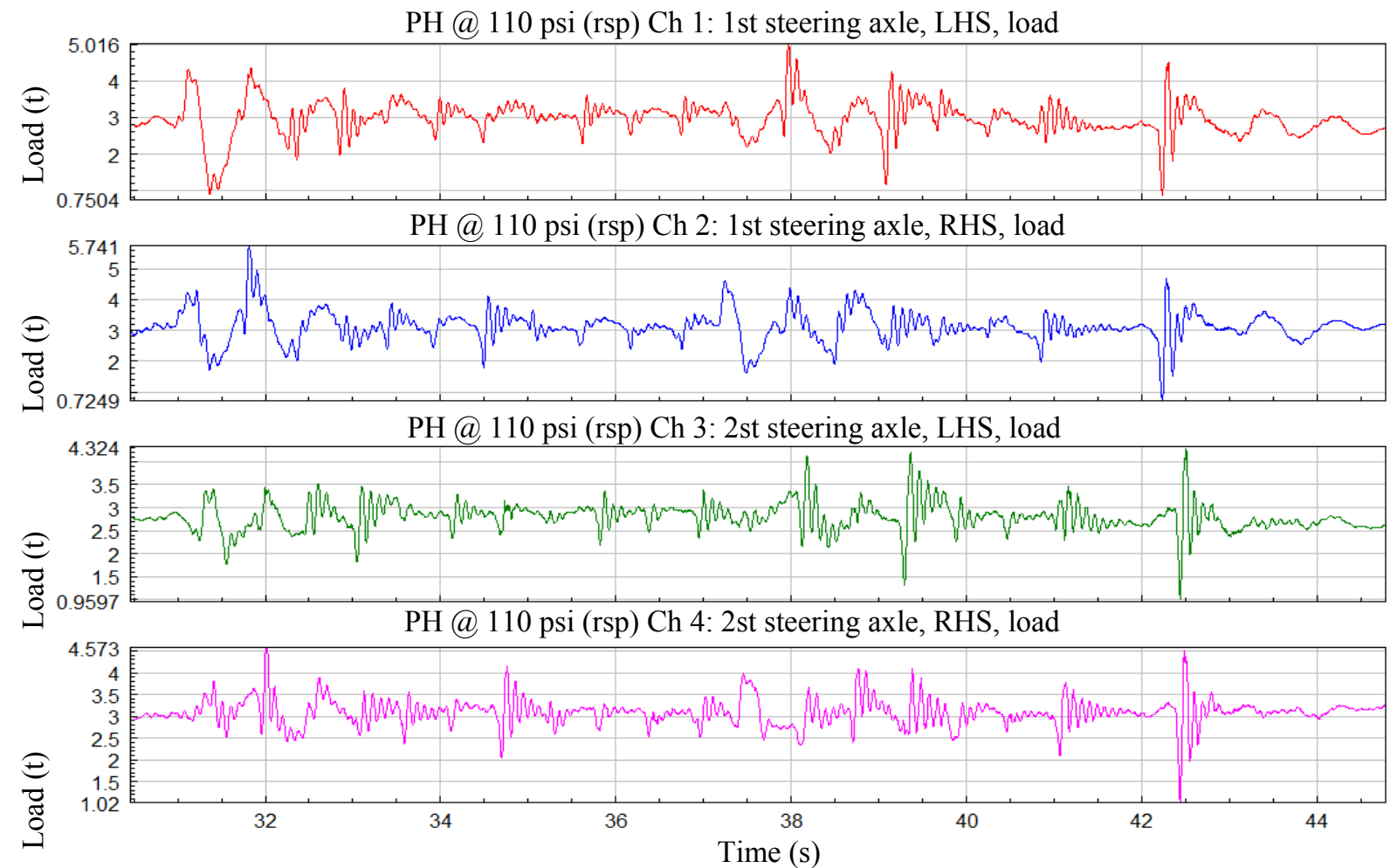

Fig. 11 Time signal—load applied on the pavement at $110 \mathrm{psi}$.

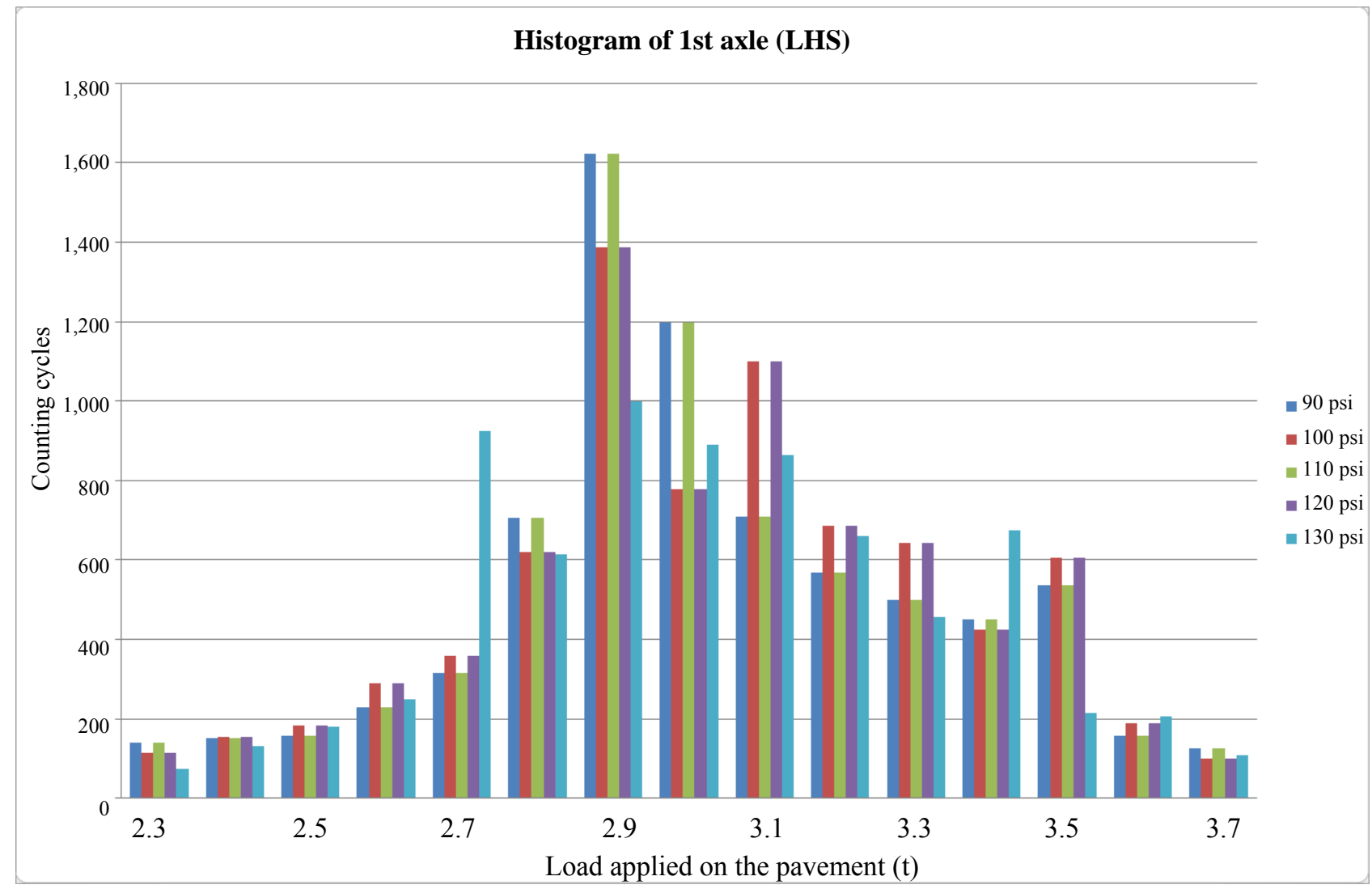

Fig. 12 Histogram of the load applied on the pavement-1st axle, LHS. 


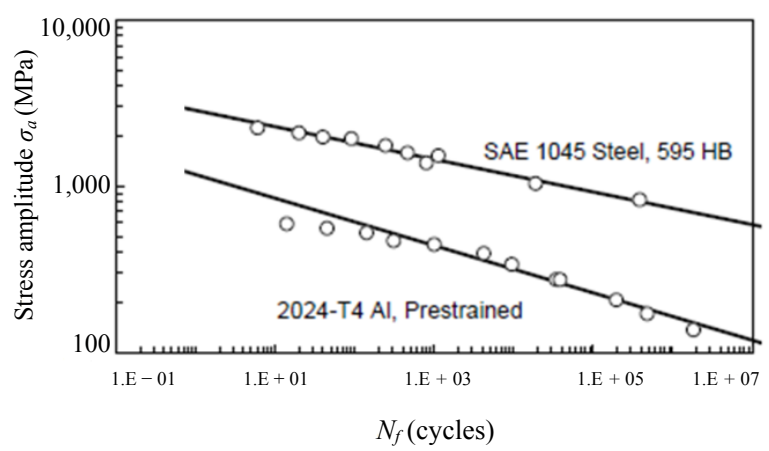

Fig. 13 Example of stress-life curve [16].

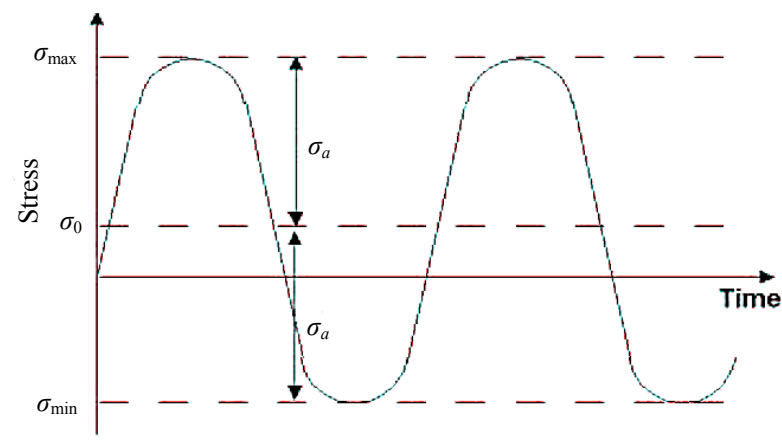

Fig. 14 Example of a sinusoidal load [16].

\section{Relative Damage Calculation}

If a test specimen is subjected to a sufficiently severe cyclic stress, a fatigue crack or other damage will develop, resulting to complete failure of the component/system [13].

The data of the different loading levels can be presented by a stress-life curve or Wöeler curve (Fig. 13).
The mentioned curve is defined through controlled samples that are tested until its complete failure with a constant frequency/amplitude sinusoidal load (Fig. 14).

Through a stress-life curve, it is possible to obtain the number of cycles until its failure $(1 . E+01$ is equal to 10) of a signal with constant load ( $\sigma_{a}$, Fig. 13). Unfortunately, just few applications have such behavior (Fig. 14).

Within this scenario, Palmgren suggested the following equation:

$$
\frac{N_{1}}{N_{f 1}}+\frac{N_{2}}{N_{f 2}}+\frac{N_{3}}{N_{f 3}}+\cdots=\sum \frac{N_{j}}{N_{f j}}=1
$$

where:

$N_{j}$ : number of cycles for each constant load;

$N_{f j}$ : number of cycles (failure) from stress-life curve, for each constant load.

Basically, Palmgren stated that a component will fail when the sum of the ratio between the number of cycles, for each segment, and the number of cycles from stress-life curves would be equal to 1 (Fig. 15).

Palmgren created this concept early in 1920, but it has been world wide spread through Miner [17], and due to that, it was named as the Palmgren-Miner rule.

On the other hand, Dowling [16] highlighted that for loads with high variation levels, it is not feasible to do the calculation as stated by Palmgren-Miner. Fig. 16 presents an example of wing acceleration (in G's) during an airplane real measurements.
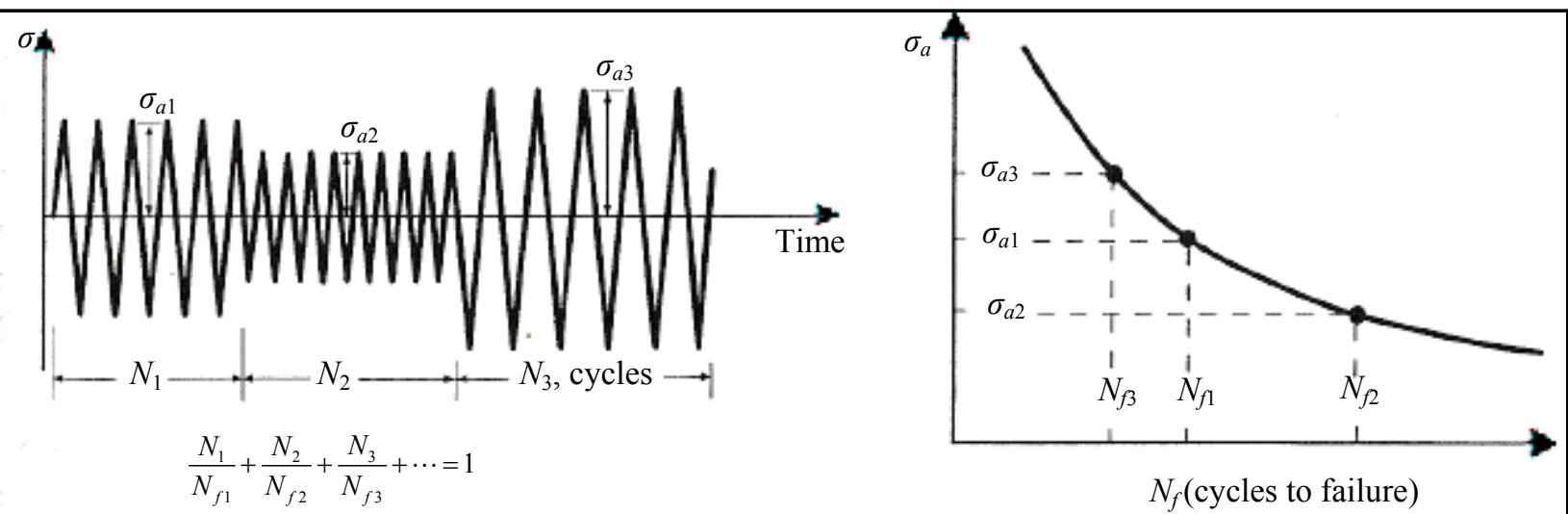

Fig. 15 Palmgren rule [16]. 


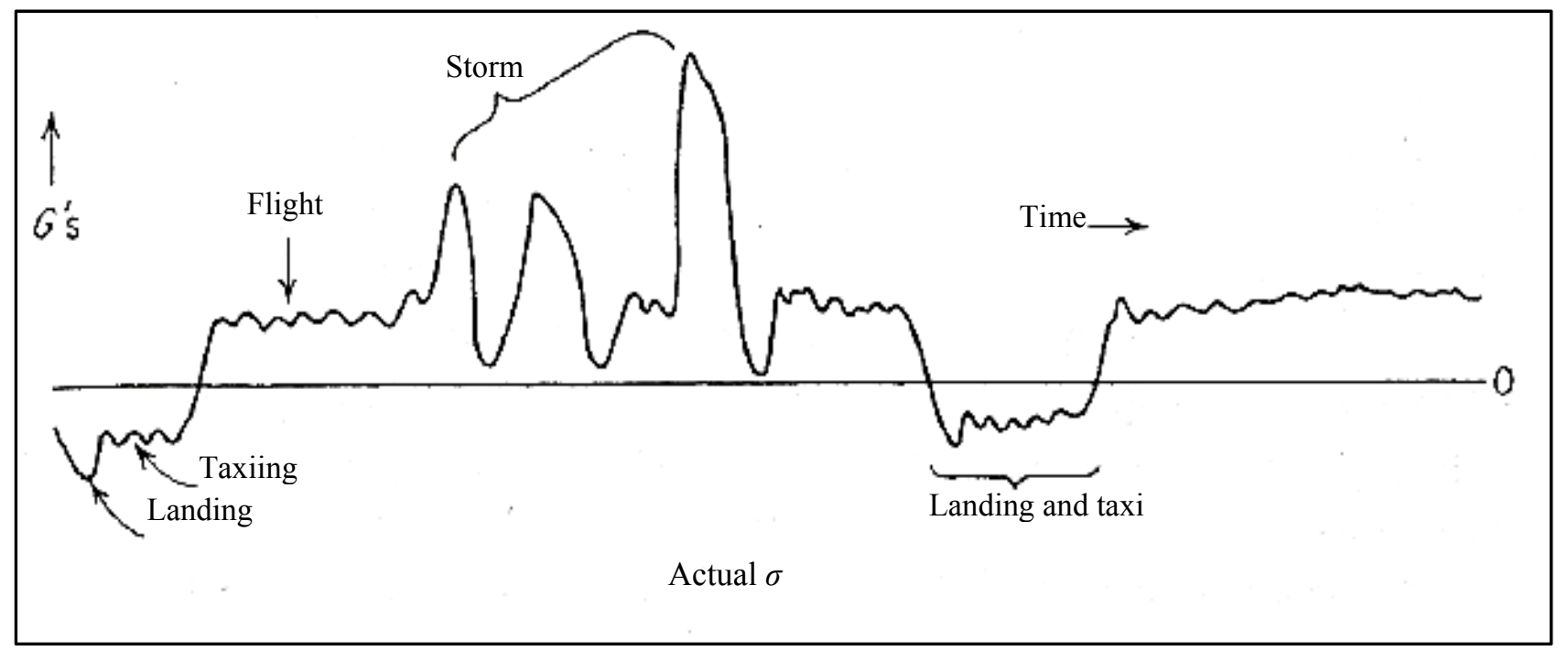

Fig. 16 Example of a real life signal-airplane wing acceleration [16].

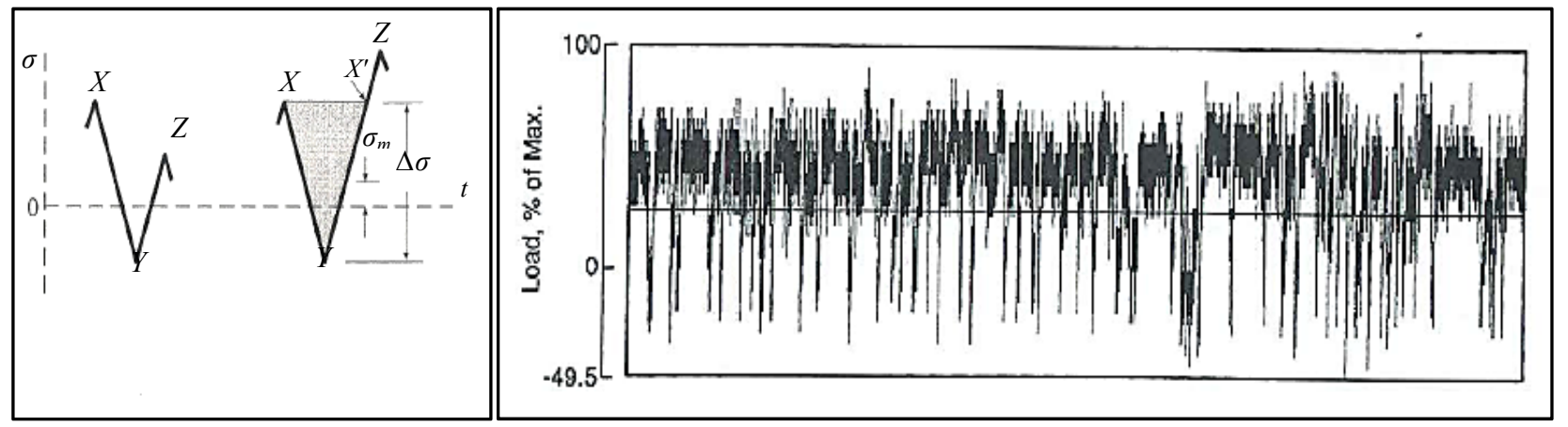

Fig. 17 Principle of the rainflow cycle counting [16].

In this way, it is necessary to adopt a procedure called rainflow cycle counting, created by Endo and Matsushi [18]. This analysis considers a cycle counting, if it follows the criteria from Fig. 17.

With the combination of the peak-valley-peak " $X-Y-Z$ " (Fig. 17), a cycle will be considered, if the amplitude variation, $\Delta \sigma_{y z}$, is equal or greater than the previous amplitude variation [18].

Finally, using the concepts from Palmgren-Miner/Endo and Matsushi, it is possible to define the following equation for the absolute damage:

$$
\sigma_{a}=\frac{\left(\sigma_{\max }-\sigma_{\min }\right)}{2}
$$

where:

$\sigma_{a}$ : average amplitude from each rainflow cycle $\left(\sigma_{\max }\right.$ and $\left.\sigma_{\min }\right)$;

$\sigma_{\max }:$ max amplitude (peak) of each rainflow cycle;

$\sigma_{\min }:$ min amplitude (valley) of each rainflow cycle.

$$
N_{f j}=\frac{1}{2}\left(\frac{\sqrt{\sigma_{\max } \cdot \sigma_{a}}}{\sigma_{f}^{\prime}}\right)^{\frac{1}{b}}
$$

where:

$N_{f j}$ : number of cycles (failure) from stress-life curve, for each constant load;

$\sigma_{f}^{\prime}$ : theoretical loading that indicates failure with zero cycle (material property);

$b$ : stress-life curve slope (material property);

$\sum \frac{N_{j}}{N_{f j}}$ : absolute damage.

Therefore, the relative damage will be the ratio between a given tire pressure damage with the baseline (110 psi).

By analysing Fig. 18, it is possible to conclude that the relative damage, regarding tire pressure, has no significant relation with the vertical load applied on the pavement. 


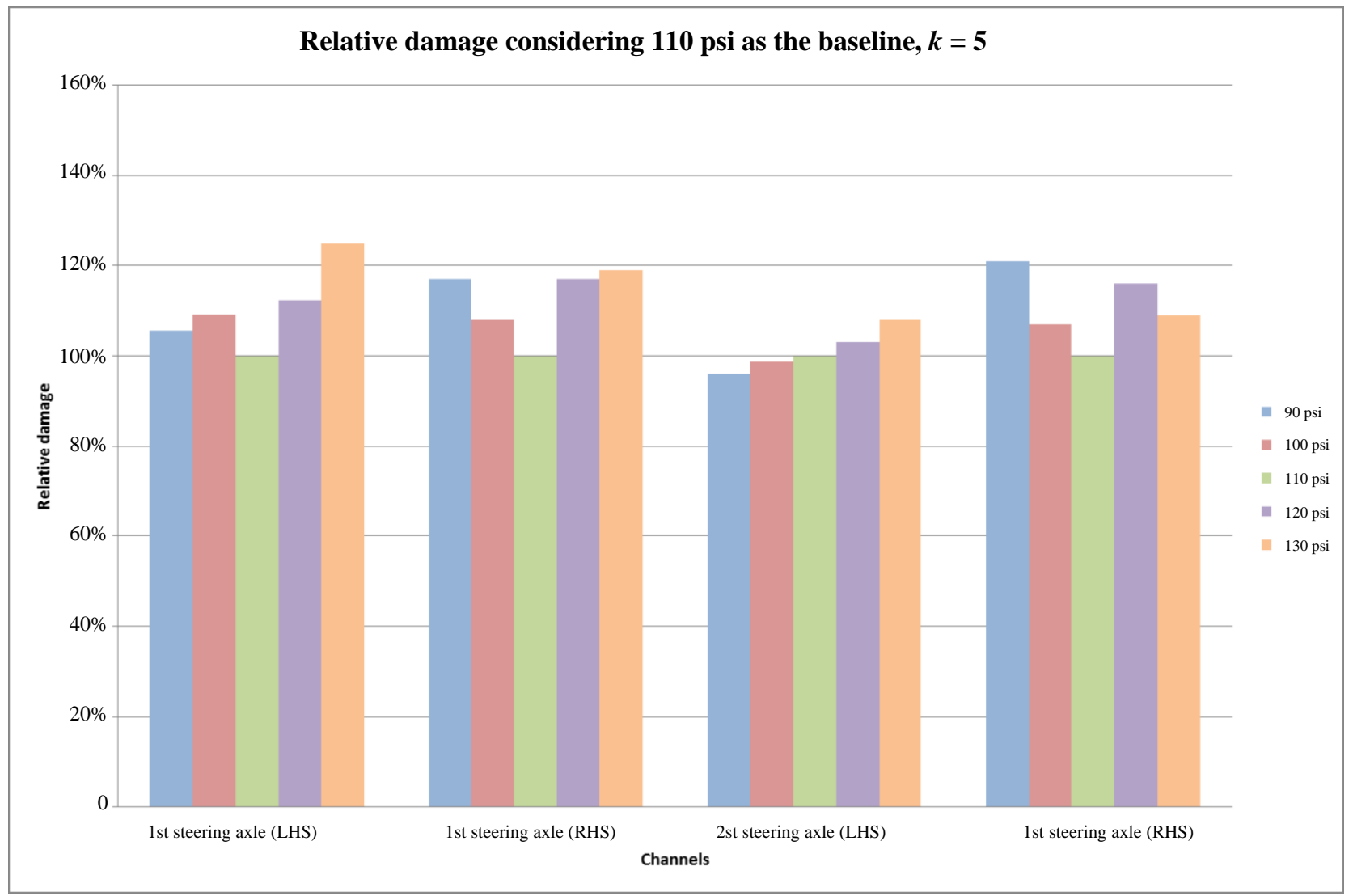

Fig. 18 Relative damage among tire pressures, $k=5$.

\section{Conclusions and Recommendation}

By applying relative damage concept, it is possible to conclude that the variation on the tire pressure, one of the parameters of the quarter car model, will not affect significantly the load applied on the pavement. However, it is recommended to repeat the same methodology in order to analyse the influence on the variation of the other quarter car model variants.

Finally, the optimized instrumentation developed could be emphasized, which could be used on any commercial vehicle with metallic suspension.

\section{References}

[1] Gallegos, M. F., Hernandez, R., Vega, D. V., and Centeno, O. F. 2010. "Evaluation of Contact Force and Pressure of Heavy Vehicle's Supersingle Tire versus Dual Tires.” SAE (Society of Automotive Engineers) technical paper 2010-01-1900.

[2] Oliveira, A., Valentim, C., Duarte, M., and Ferreira, R. 2008. “Tire Pressure Impact on Structural Durability Tests
Results.” SAE technical paper 2008-36-0041.

[3] Sayers, M. W., Gillespie, T. D., and Queiroz, C. A. V. 1986. The International Road Roaghness Experiment: Establishing Correlation and a Calibration Standard for Measurements. Washington D. C.: The World Bank.

[4] Gillespie, T. 1992. Fundamentals of Vehicle Dynamics. Warrandale: Society of Automotive Engineers.

[5] Wang, H., and Al-Qali, I. L. 2010. "Evaluation of Surface-Related Pavement Damage Due to Tire Braking.” Road Materials and Pavement Design 11 (1): 101-21.

[6] Al-Qadi, L., Elsefi, M. A., and Yoo, P. J. 2005. "Characterization of Pavement Damage Due to different Tire Configurations." Journal of the Association of Alphalt Paving Technologists 84 (1): 921-62.

[7] Myers, L. A., Roque, R., Ruth, B. E., and Drakos, C. 1999. "Measurement of Contact Stresses for Different Truck Tire Types to Evaluate Their Influence on Near-Surface Cracking and Rutting." Transportation Research Record 1665 (23): 175-84.

[8] Tielking, T., and Roberts, F. L. 1987. "Tire Contact Pressure and Its Effect on Pavement Strain.” Journal of Transportation Engineering 113 (1): 56-71.

[9] Andolfato, R. P., Camacho, J. S., and Brito, G. A. 2004. Extensometria Básica (Basic Principles of 
Externsometers). Ilha Solteira: UNESP (State University of Sao Paulo). (in Porguguese)

[10] Lima, W. M., Neto, J. S. R., and Lima, A. M. N. 2008. "Measurement and Control of Deformation on a Flexible Beam Using Shape Memory Alloy." In Proceedings of 3rd ABCM (Brazilian Association of Engineering and Mechanical Science) Symposium Series in Mechatronics, 1-8.

[11] Gallina, R. 2003. "Os Extensômetros Elétricos Resistivos: Evolução, Aplicações e Tendências (Electrical Resistance Extensometers: Evolution, Application and Trends)." M.Eng. thesis, Universidade de São Judas Tadeu. (in Portuguese)

[12] Hannah, R. L., and Reed, S. E. 1992. Strain Gage Users' Handbook. London: Chapman \& Hall.

[13] Amoros, R. T. 2008. “Avaliação de Tensões Residuais Em Chapas Planas de Aço Carbono, Destinadas a Processo de Corte a Laser, Pelo Método da Anisotropia Planar (Residual Stresses Evaluation in Flat Carbon Steel Plates, Applied to Laser Cutting Process, by Anisotropic Planar
Method)." M.Eng. thesis, Instituto de Engenharia do Parana. (in Portuguese)

[14] Rodrigues, N. 2012. "Caracterização Estática e Dinâmica de um Sensor de Forças/Momentos (Static and Dynamic Characterization of a Force/Moment Sensor).” M. Eng. thesis, Universidade Nova de Lisboa. (in Portuguese)

[15] Silva, W. J. S., and Assis, W. S. 2012. "Monitoração Estrutural e Instrumentação Virtual Aplicados ao Ensino Experimental de Engenharia Civil (Structrural Monitoring and Virtual Instrumentation Applied to the Experimental Classes in Civil Engineering)." In Proceedings of 40th Congresso Brasileiro de Educação em Engenharia, 1-12.

[16] Dowling, N. E. 2012. Mechanical Behavior of Materials: Engineering Method for Deformation, Fracture and Fatigue, 4th ed.. New Jersey: Pearson.

[17] Miner, A. 1945. "Cumulative Damage in Fatigue." Journal of Applied Mechanics 45 (1): 156-64.

[18] Endo, T., and Matsushi, M. 1968. Fatigue of Metals Subjected on Varying Stress. Jukvoka: Japan Society of Mechanical Engineering. 